\title{
Pattern And Duration Of Exclusive Breastfeeding
}

\section{G Singh}

\section{Citation}

G Singh. Pattern And Duration Of Exclusive Breastfeeding. The Internet Journal of Nutrition and Wellness. 2005 Volume 2 Number 2.

\section{DOI: $\underline{10.5580 / 1 \mathrm{ea} 3}$}

\begin{abstract}
The pattern and duration of breastfeeding varies considerably among women belonging to different sections of the population.

Aim: The objective of this paper was to determine the mean duration of exclusive breastfeeding for a sample of women and to test the significance of difference between feeding at fixed time and feeding on demand of child.
\end{abstract}

Method: A sample of 70 women was interviewed at immunization centre in Varanasi, where they came with their youngest child for vaccination. Mean and sd of duration of exclusive breastfeeding (months) for women feeding at fixed time and on demand were calculated and compared using $t$ test.

Result: The mean duration of exclusive breastfeeding was observed slightly higher in women feeding at fixed time $(5.08 \pm 1.23)$ than those on demand of the child $(4.95 \pm 1.15)$ though, the difference was found not statistically significant.

Conclusion: All women should practice exclusive breastfeeding from birth upto 4 to 6 months. Though the mean duration observed here lied in this interval, but it ranged from 2.50 to 8.50 months.

\section{INTRODUCTION}

Exclusive breastfeeding is the practice of feeding only breast milk (including expressed breast milk) and allows the baby to receive vitamins, minerals or medicines. Water, breastmilk substitutes, other liquids and solid foods are excluded. WHO World Health Assembly in 2001 resolved that exclusive breastfeeding for the first six months is the most appropriate infant feeding practice. ${ }_{1}$ An ideal duration for exclusive breastfeeding universally accepted was 4 to 6 months however, recent developments suggest exclusive breastfeeding to continue upto six months.2,3

The aim of this paper was to determine mean duration of exclusive breastfeeding of a group of women who had delivered a child within last one year from survey date. Further, to test was there any statistically significant difference between mean duration of exclusive breastfeeding for women feeding at fixed time and those feeding on demand of child.

\section{METHODS}

A sample of 70 women was selected from child immunization centre at Varanasi in the year 2004 where they came with their child for vaccination. Sample size was calculated on the basis of descriptive outcome measures considering the estimates of similar previous studies. Women included in the study were those whose youngest child was aged less than or equal to one year on the date of interview. Women were interviewed through a study proforma which included general information, sociodemographic status, marital duration, number of conceptions, number of births, birth intervals, date of birth of youngest child, duration of exclusive breastfeeding, pattern of breastfeeding like full, partial, at fixed time or on demand. The duration of exclusive breastfeeding (in months) here refers to the period which begins when the first breast milk is given to the child and ends at the time when full breastfeeding terminates with the introduction of semi-solid or liquid food supplements along with breastfeeding.

\section{RESULTS}

The age range of women under study was 20-34 years. Women were selected regardless of parity. A large proportion of women were housewives belonging to middle 
class family and coming from urban area. Out of a total of 70 women, 33 practiced exclusively breastfeeding their youngest child at fixed time whereas, 37 on demand of the child.

The analysis of data revealed some interesting results as shown in Table-1.

\section{Figure 1}

Table 1

\begin{tabular}{|l|l|l|}
\hline $\begin{array}{l}\text { Pattern of Exclusive } \\
\text { Breastfeeding }\end{array}$ & $\begin{array}{l}\text { Duration of Exclusive } \\
\text { Breastfeeding (month) } \\
\text { Mean } \pm \text { SD } \\
\text { (min... max.) }\end{array}$ & $\begin{array}{l}\text { Between the group } \\
\text { comparison } \\
\text { (Unpaired t test) }\end{array}$ \\
\hline $\begin{array}{l}\text { At Fixed Time } \\
(n=33)\end{array}$ & $\begin{array}{l}5.08 \pm 1.23 \\
(3.00,8.50)\end{array}$ & $\begin{array}{l}\mathrm{t}=0.46 \\
p=0.65 \\
\text { Not Significant }\end{array}$ \\
\hline $\begin{array}{l}\text { On Demand } \\
(\mathrm{n}=37)\end{array}$ & $\begin{array}{l}4.95 \pm 1.15 \\
(2.50,8.00)\end{array}$ & \\
\hline $\begin{array}{l}\text { Total } \\
(\mathrm{n}=70)\end{array}$ & $\begin{array}{l}5.01 \pm 1.18 \\
(2.50,8.50)\end{array}$ & \\
\hline
\end{tabular}

The duration of exclusive breastfeeding of total subjects was found to be varying from a minimum of 2.50 months to a maximum of 8.50 months though the mean duration was observed 5.01 months. A better descriptive measure for such situation may be median, which was observed 5.00 months indicating that $50 \%$ of total subjects exclusively breastfed for less than or equal to 5 months while $50 \%$ for greater than or equal to 5 months. When total subjects were divided into two groups on their pattern of exclusive breastfeeding as at fixed time and on demand, a similar picture appeared. The mean duration was more or less same whether they practiced feeding at fixed time $($ mean $=5.08)$ or on demand of the child (mean=4.95). Between the groups comparison of mean using unpaired $\mathrm{t}$ test resulted not statistically significant $(\mathrm{t}=0.46$, $\mathrm{p}=0.65)$.

\section{Figure 2}

Figure 1: Duration of breastfeeding in months

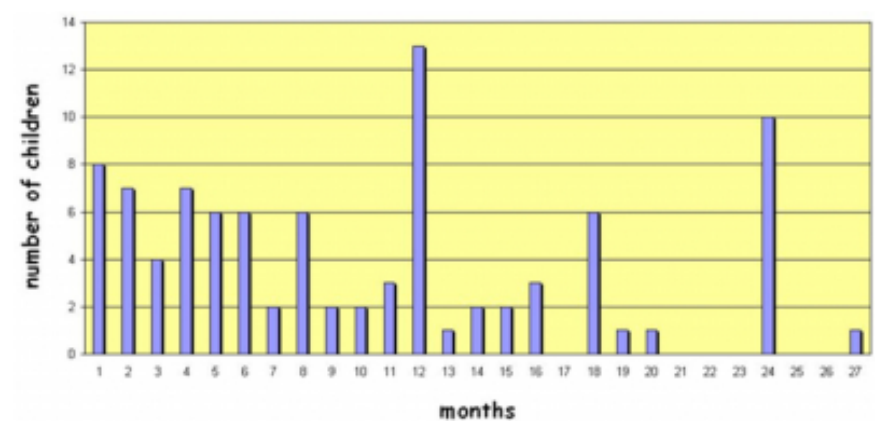

\section{Figure 3}

Figure 2: Liquids administered during lactation (number of children)

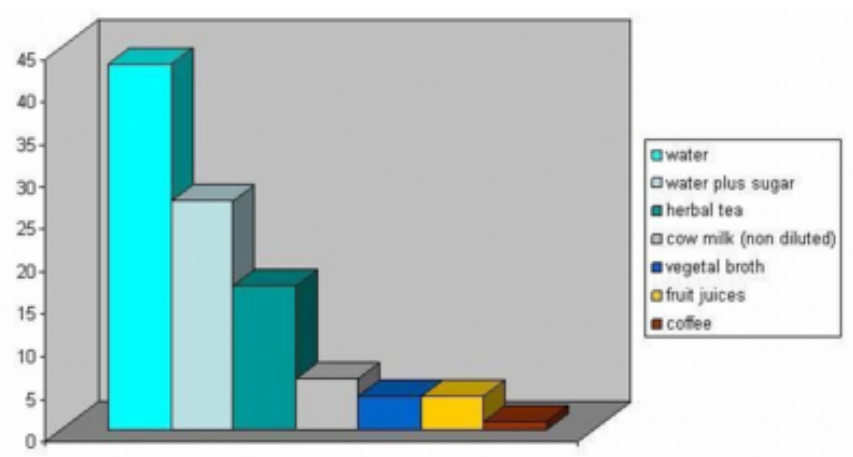

\section{Figure 4}

Figure 3: Frequency of complementary food administration

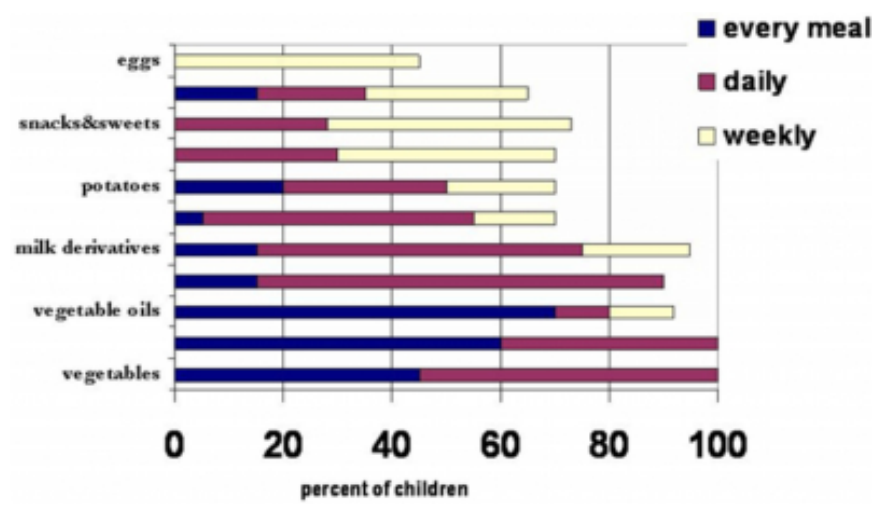

\section{DISCUSSION}

Breastfeeding besides providing required nutrients for proper growth and development of a child ensures in developing immunity to protect from infections thereby promoting child survival. Exclusive breastfeeding should be promoted up to six months of age of infants thereafter adequate complementary items should be introduced along with breastfeeding. Partial breastfeeding may continue up to two years of age and beyond. Mean duration of exclusive breastfeeding observed in the present study though lied in 4 to 6 months recommended duration but it ranged from two and half months to eight and half months. This small study shows some interesting trend, which may be further examined studying a large sample incorporating other facet of the phenomenon.

\section{KEY MESSAGES}

1. Mean duration of exclusive breastfeeding was found 5.01 months, which was within the recommended range of 4 to 6 months.

2. There was no significant difference between mean 
duration of exclusive breastfeeding of women feeding at fixed time and those feeding on demand of the child.

\section{CORRESPONDENCE TO}

Dr.Girish Singh 6, Ganga Bagh Colony, Lanka, Varanasi 221005 India Phone: 0542-2367304 e-mail: drgirishsingh@ yahoo.com

\section{References}

1. WHO. Infant and young child nutrition resolution 54.2 of the World Health Assembly. Resolutions and Decisions of 54th World Health Assembly, 14-22 May 2001.

2. Boland M. Exclusive breastfeeding should continue to six months. Paediatrics and Child Health 2005; 10 (3): 148.

3 . WHO. The optimal duration of exclusive breastfeeding. Report of an expert consultation. Geneva, 28-31 March 2001. 


\section{Author Information}

Girish Singh

Biostatistics unit, Department of Basic Principles, Institute of Medical Sciences, Banaras Hindu University 